\title{
Biomechanical Investigation of Different Tying Forces on Knot Security
}

\author{
Sean Wei Yi Lee', Yoke-Rung Wong'* and Shian-Chao Tay ${ }^{2,3,4}$ \\ ${ }^{1}$ National University of Singapore, Yong Loo Lin School of Medicine \\ ${ }^{2}$ Biomechanics Laboratory, Singapore General Hospital, Singapore \\ ${ }^{3}$ Department of Hand Surgery, Singapore General Hospital, Singapore \\ ${ }^{4}$ Duke-NUS Medical School, Singapore \\ *Corresponding author: Wong Yoke Rung,Singapore General Hospital 20 College Road, Academia, Level 1, Biomechanics Lab, \\ Singapore
}

\section{ARTICLE INFO}

Received: 幽 April 09, 2019

Published: 幽 April 23, 2019

Citation: Sean WY Lee, YR Wong, SC Tay. Biomechanical Investigation of Different Tying Forces on Knot Security. Biomed J Sci \& Tech Res 17(2)2019. BJSTR. MS.ID.002985.

Keywords: Wound Closure; Cyclic Testing; Knot Slippage; Suture Breakage
ABSTRACT

Background: Knowing the relationship between tying force and knot security could reduce knot failure due to inconsistent tying forces. This study presents a new experimental set-up that enables testing of a knot configuration tied with a measured force.

Methods: Five tying forces 1N, 2N, 3N, 4N, 5N were investigated. The surgeon's knot with 3 throws $(2-1-1)$ was used to suture two $70 \times 15 \mathrm{~mm}$ porcine skins together with Prolene 4.0. Ten specimens were involved in each group. The specimen was subjected to 2 stages of cyclic testing of 200 cycles. Stage I was subjected to a cyclic load of $2 \mathrm{~N}-10 \mathrm{~N}$ and Stage II, a cyclic load of $2 \mathrm{~N}-20 \mathrm{~N}$. Survival rate of the knots for each stage was calculated. Knots that survived were subjected to static testing. Ultimate tensile strength (UTS) required to cause knot failure was recorded.

Results: $3 \pm 0.5 \mathrm{~N}$ tying force had the highest survival rate of $100 \%$ in stage I and $90 \%$ in stage II. This result contradicted static testing results which showed that tying forces between $3 \mathrm{~N}$ to $5 \mathrm{~N}$ could achieve the highest UTS without statistically significance. Another finding was that knots tied with different tying forces behave independently under various cyclic loading conditions.

Conclusion: A new experimental setup to test a knot configuration with different tying force was presented. Based on static and cyclic testing, we found that $3 \pm 0.5 \mathrm{~N}$ is the optimum force needed to tie a surgeon's knot with 3 throws for maximal knot security using Prolene 4.0.

\section{Introduction}

Wound closure by suturing is practiced frequently among all clinicians. Knot failure including knot slippage and suture breakage is the most common failure mechanism that prevents wound recovery back to their original anatomical positions [1,2]. Wound dehiscence can potentially complicate wound healing. One major factor determining knot failure is its security [3]. Knot security is defined as the survival of a suture knot after a continuous load has been applied $[4,5]$. A poorly secured knot has a higher chance of failure at the knot as the knot is the weakest point of the suture
[6-9]. Many studies have investigated various factors affecting knot security. Eric et al. investigated the effects of different surgical knotting techniques, suture materials, suture sizes, and number of throws on knot security of square, surgeon's, and sliding knots used in oral and maxillofacial surgery [4]. Similar studies were carried out by Lo et al. [10] and Ilahi et al. [11] for arthroscopic soft tissue repairs. All of the studies confirmed that the knot security of different knotting techniques that had undergone static or cyclic testing can possess different biomechanical performance. 
However, surgeons' fatigue towards the end of the day and tie knots with inconsistent forces [12]. Tying a force too loose or too tight can affect the knot security and hence have negative effects on wound healing [13]. Knowing the optimum force required to tie a secure knot would be a step closer in making sure that knots are tied consistently. To the best of our knowledge, the relationship between tying force and knot security has yet been studied. In the present study, we propose an experimental set-up that enables testing of a knot configuration which is tied with a measured force. This setup mimics the situation when surgeons are fatigue and have the tendency to tie knots with inconsistent forces. We hypothesize that there is an optimum tying force to tie the most secure knot.

\section{Materials and Method}

\section{Specimen Preparation}

Fresh frozen porcine skin was used in the experiments. The porcine skin was defrosted to room temperature using $0.9 \%$ saline solution before conducting the experiment. It was cut to a size of $140 \times 15 \mathrm{~mm}$ Figure 1. A laceration was made in the middle of the porcine skin along a longitudinal direction to simulate a complete open skin wound. Each side of the porcine skin measured 70x15mm. Prolene 4-0 (Ethicon, US), a single stranded synthetic nonabsorbable polypropylene monofilament suture was used to stitch the skin. The surgeon's knot was chosen as the knot technique of choice in our study because it is a simple and commonly adopted knot technique that has been shown to be superior to square and sliding knots in terms of knot security [4, 14-16]. For each specimen, a surgeon's knot with 3 throws (2-1-1) was made. The distance of the stitch to the edge of the wound was kept constant at $10 \mathrm{~mm}$. Five tying forces, $1 \mathrm{~N}, 2 \mathrm{~N}, 3 \mathrm{~N}, 4 \mathrm{~N}, 5 \mathrm{~N}$ were adopted to tie the suture. A tolerance of $0.5 \mathrm{~N}$ was controlled at each tying force. This would give a range of the tying force, i.e. $1 \pm 0.5 \mathrm{~N}$. Ten samples were tied using each force giving a total of 50 samples.

An Instron 3343 (Instron Corp., Canton MA, USA) mechanical tester was used to measure the tying force. As shown in Figure 2, the suture was looped around 2 metal bars one on top of the other. For the $2^{\text {nd }}$ and $3^{\text {rd }}$ throw, the suture was looped around the bottom bar first, pulled upward and rounded the upper bar with a controlled downward force. Based on the force equilibrium, both upward and downward tension of the suture gave the resultant force as measured by the mechanical tester. Hence, the actual force for knot tying would be half of the force that was being measured, eg $2 \mathrm{~N}$ would be pulled to $4 \mathrm{~N}$. However, we did not measure the force of the first throw as making a simple cross of suture without any taut could not warrant a stable enough force to measure. Therefore, only forces of the $2^{\text {nd }}$ and $3^{\text {rd }}$ throws were measured.

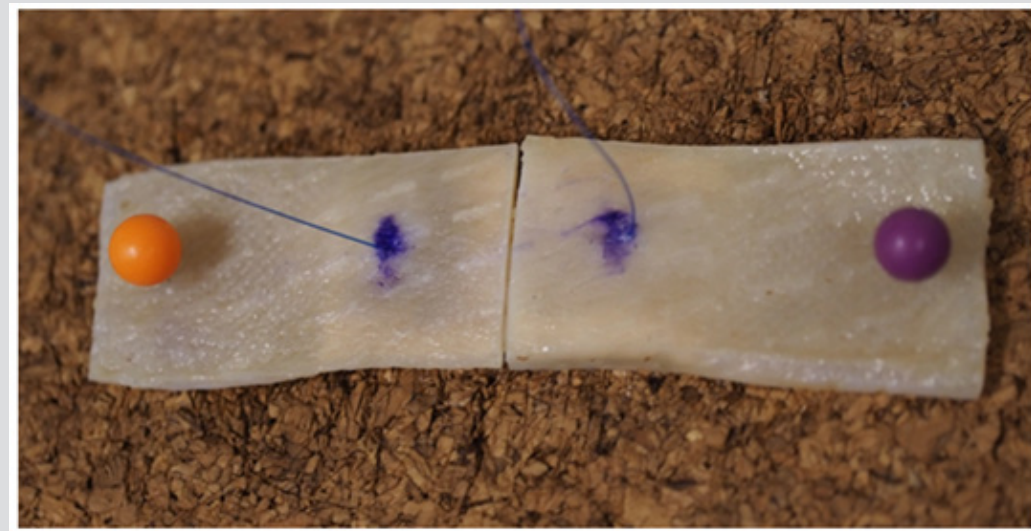

Figure 1: Specimen of porcine skin 70x15mm. A longitudinal laceration was made and a 10mm distance from the edge to the suture was kept constant.

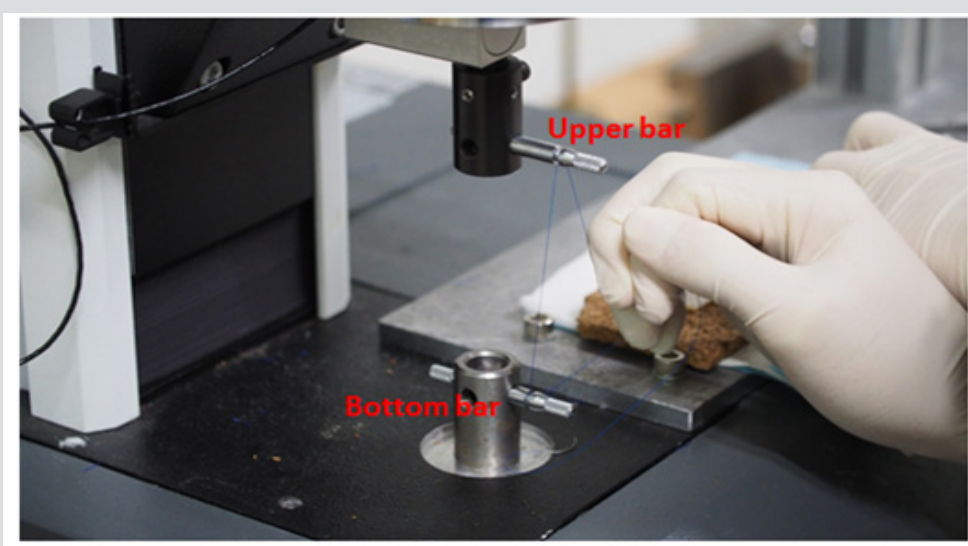

Figure 2: The suture was looped around 2 metal bars one on top of the other. For the 2nd and 3rd throw, the suture was looped around the bottom bar first, pulled upward and rounded the upper bar with a controlled downward force. 


\section{Biomechanical Testing}

Cyclic Testing: Cyclic tests were performed on E-1000 Dynamic Tester (Instron Corp., Canton MA, USA). After suturing the porcine skin with the respective forces, the ends of the porcine skin were mounted onto pneumatic grippers with blasted clamping surfaces. The distance between the two grippers were maintained in such a way that the specimen would not be taut figure 3. Cyclic testing was divided into 2 stages. Stage I comprised of the 1 st 100 cycles with a loading force of 2-10N. Stage II was the 2nd 100 cycles with a higher loading force of 2-20N. A frequency of $1 \mathrm{~Hz}$ was used to cyclically load the specimens under both stages. Both knot slippage and suture breakage was considered as the failure criteria of the tests. For knot slippage, a $6 \mathrm{~mm}$ elongation of crosshead displacement is chosen according to the study done by Baums et al. [9] A high resolution video recorder was used to record the failure mechanisms in knot security.

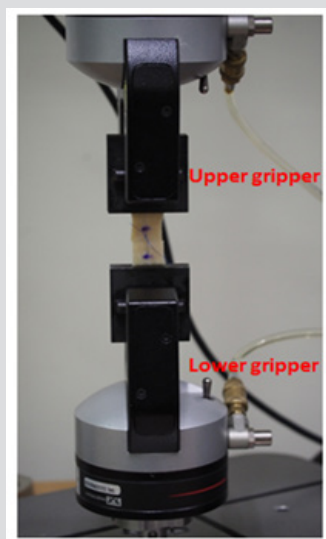

Figure 3: After completing the suture, the specimen was placed in between 2 pneumatic grippers such that the specimen would not be taut.

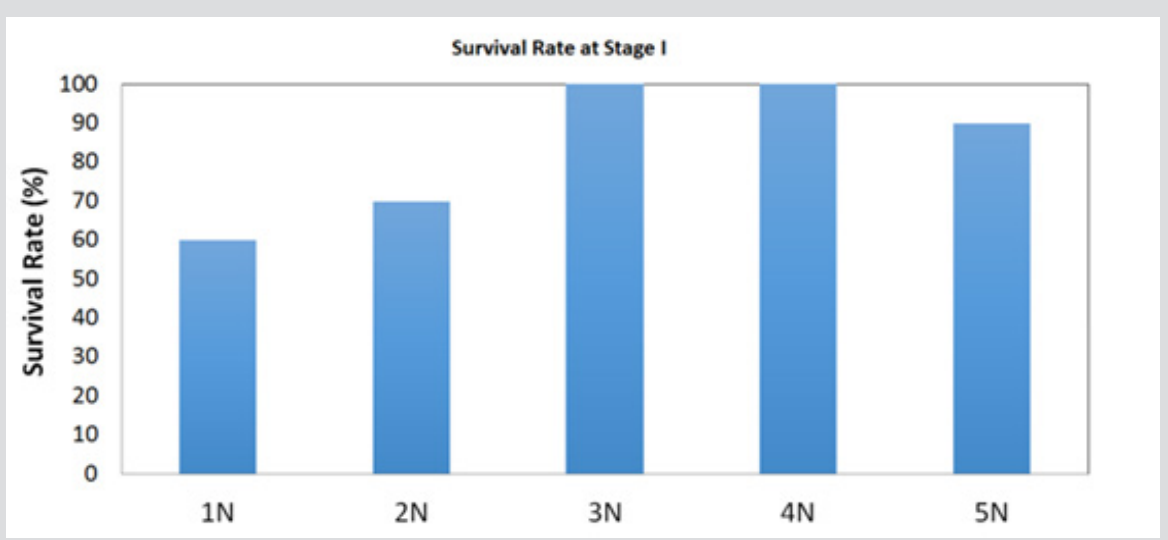

Figure 4: Survival of knots at stage I.

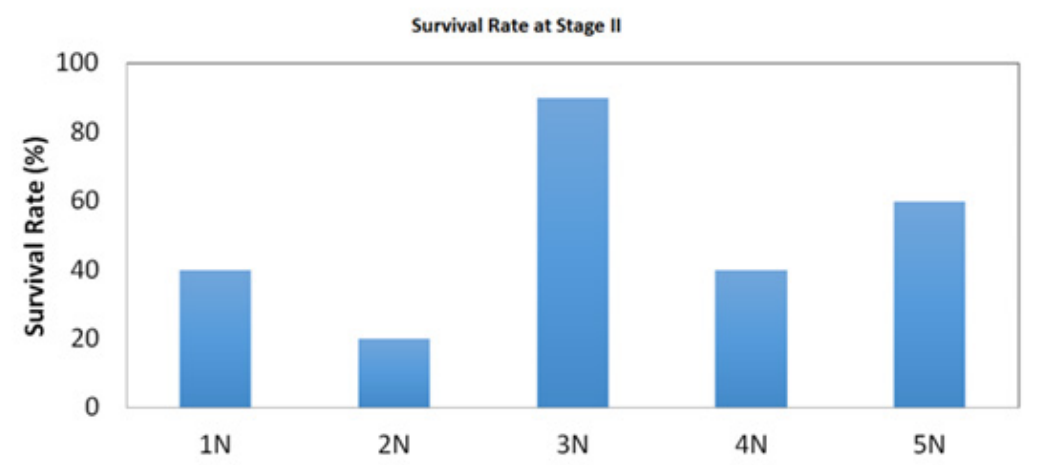

Figure 5: Survival of knots at stage II. 
Survival rate of surgeon's knots in Stage I and II was calculated as followed: (number of specimens that survived after 100 cycles of the stage)/10. A bar graph showing survival rate against tying force is presented in Figure 4 and 5.

Static Testing: Surgeon's knots that survived cyclic testing were subjected to static testing. The knot was pulled to failure at a rate of $20 \mathrm{~mm} / \mathrm{min}$. Ultimate tensile strength (UTS) needed to pull the knots to failure were recorded.

Statistical Test: Mean and standard deviation were calculated for the sutures subjected to static testing. Student t test was conducted to calculate the $\mathrm{p}$ value. A $\mathrm{p}$ value less than 0.05 is statistically significant.

\section{Results}

\section{Cyclic Testing}

With a cyclic force of $2 \mathrm{~N}-10 \mathrm{~N}$ in stage I, tying forces of $3 \mathrm{~N}$ and $4 \mathrm{~N}$ had the highest survival rate of $100 \%$ Figure 4 . Tying force of $1 \mathrm{~N}$ was the least desirable with a survival rate of $60 \%$. Tying force of $2 \mathrm{~N}$ achieved a survival rate of $70 \%$ and $5 \mathrm{~N}$ achieved a survival rate of $90 \%$. When the cyclic force increased to $2 \mathrm{~N}-20 \mathrm{~N}$ in stage II, $3 \mathrm{~N}$ tying force retained the highest survival rate of $90 \%$ Figure 5 . Tying force of $2 \mathrm{~N}$ was the least desirable with a survival rate of $20 \%$. Tying force of $1 \mathrm{~N}$ achieved a survival rate of $40 \%, 4 \mathrm{~N}$ achieved $40 \%$ and $5 \mathrm{~N}$ achieved a survival rate of $60 \%$.

\section{Static Testing}

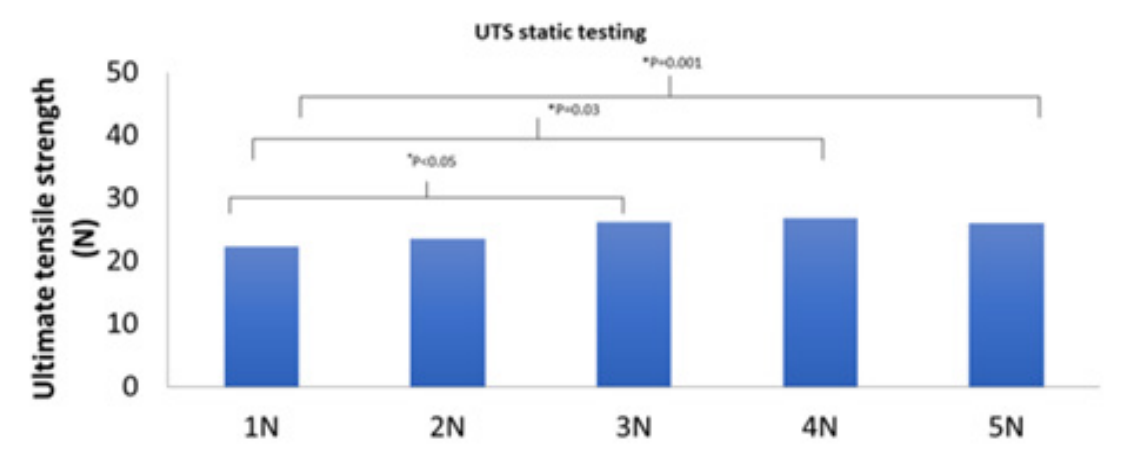

Figure 6: UTS of knot failure with different tying forces. $\left(^{*}\right)$ shows a statistically significant difference between groups.

As shown in Figure 6, knots tied with 4N that survived cyclic testing had the highest mean UTS of $26.8 \mathrm{~N}$ while knots tied with $1 \mathrm{~N}$ that survived cyclic testing had the lowest mean UTS of $22.3 \mathrm{~N}$. Statistical testing showed that UTS of tying forces $3 \mathrm{~N}, 4 \mathrm{~N}, 5 \mathrm{~N}$ were significantly different $(\mathrm{p}<0.05)$ when compared to UTS of tying force $1 \mathrm{~N}$. UTS of tying forces $1 \mathrm{~N}, 3 \mathrm{~N}, 4 \mathrm{~N}$ and $5 \mathrm{~N}$ were not significantly different $(p>0.05)$ when compared to UTS of tying force $2 \mathrm{~N}$.

\section{Failure Mechanisms in Knot Security}

Knot slippage caused all tested knots to fail during cyclic testing. For static testing, all knots failed due to suture breakage at the knot.

\section{Discussion}

In this study, we investigated 5 different tying forces i.e. $1 \mathrm{~N}, 2 \mathrm{~N}$, $3 \mathrm{~N}, 4 \mathrm{~N}, 5 \mathrm{~N}$. We took $5 \mathrm{~N}$ tying force to be the limit because pulling to a force greater than $5 \mathrm{~N}$ (actual force $=10 \mathrm{~N}$ ) was difficult to achieve. We chose Prolene 4-0 as the suture material for surgeon's knot for 2 reasons: the UTS of the suture material Prolene is not high and easy to slip due to its smooth surface. We are of opinion that using a slippery suture material with low mechanical strength for simple knotting technique such as a surgeon's knot can validate our experimental setup so that it can be easily adopted for testing other suture materials and knotting techniques. For cyclic testing, we divided the test into two stages. Stage I comprised the 1 st 100 cycles with a cyclic load of $2-10 \mathrm{~N}$ while the 2nd 100 cycles with 2-10N were tested in stage II. Baum et al. [9] suggested to divide cyclic testing of knot security into 8 power levels with an increase in $10 \mathrm{~N}$ for each level for every 100 cycles up to $80 \mathrm{~N}$. This was unnecessary in the present experimental setup because all of the Prolene 4.0 broke by the tensile load in between $20-30 \mathrm{~N}$, based on the static testing results.

As shown in Figure 4, all knots tied had a survival rate of more than $60 \%$. In particular, $3 \mathrm{~N}$ and $4 \mathrm{~N}$ had a survival rate of $100 \%$. Hence, we suggest that the optimum range of tying force is $3 \mathrm{~N}$ and $4 \mathrm{~N}$ under the cyclic loading below $10 \mathrm{~N}$. On the other hand, it is also possible to include $5 \mathrm{~N}$ tying force in the optimum range since its survival rate stood at $90 \%$, which is very close to a survival rate of $100 \%$. We are of opinion that $1 \mathrm{~N}$ and $2 \mathrm{~N}$ tying forces could be insufficient to tie a knot, which resulted into a lower survival rate (60\% for $1 \mathrm{~N}$ tying force and $70 \%$ for $2 \mathrm{~N}$ tying force). For stage II, increment of the cyclic load would affect the optimum tying force and hence the survival rate. As shown in Figure 5, the survival rate of knots tied with $3 \mathrm{~N}$ tying force dropped to $90 \%$ but was still the tying force that obtained the highest survival rate. In fact, the survival rate of other tying forces also dropped. $1 \mathrm{~N}$ tying force achieved 40\%, 2N tying force achieved 20\%, 4N tying force achieved $40 \%$ and $5 \mathrm{~N}$ tying force achieved $60 \%$. We were aware that $4 \mathrm{~N}$ and $5 \mathrm{~N}$ tying force had $60 \%$ and $30 \%$ drop in their survival rates. This could be attributed to the reason that tying a suture with too much force can in turn cause the suture to be even weaker due to a decrease in knot security.

On the other hand, the $1 \mathrm{~N}$ and $2 \mathrm{~N}$ tying force had a $20 \%$ and $50 \%$ drop of their survival rates respectively. We believed that too loose 
a knot would give it no holding strength when subjected to greater cyclic load. Our initial thoughts were that the best performing tying forces were to follow up from stage I. However, the experimental results showed that $4 \mathrm{~N}$ tying force had the most significant drop in survival rate. This could be inferred that different knot tying forces would perform independently under various cyclic loading conditions. Therefore, $3 \mathrm{~N}$ was still the optimum tying force because it achieved the highest survival rates under different cyclic loads.

An ideal biomechanical test of knot security is one that best simulates reality. Rarely would a patient pull a wound with a single large force. Wound dehiscence occurs due to continuous forces applied to a suture throughout the day. In our study, static testing revealed that tying forces between $3 \mathrm{~N}$ to $5 \mathrm{~N}$ could achieve the highest UTS before suture breakage. However, this contradicted cyclic testing results which showed that tying knots with $4 \mathrm{~N}$ and $5 \mathrm{~N}$ did not achieve significantly better results. Hence, we could confirm that the cyclic testing is a more physiological testing method to investigate the knot tying.

Previous studies have shown that a wide range of tying forces are used amongst expert surgeons [17-20]. Stefan Neuhofer et al demonstrated that the overall range of tying force used by surgeons regardless of suture technique and thread type was $3 \mathrm{~N}-63 \mathrm{~N}$ with a mean of $15 \mathrm{~N}$ [17]. However, knots were tested by pulling the knot to failure using a single load. With this span of varied forces, it is difficult to know what exactly the correct range of tying force is. Our study has shown that $3 \pm 0.5 \mathrm{~N}$ tying force would give a secured knot. A knot with more dedicated tying force improves the precision and also reduces the chance of knot slippage in clinical practice. This can help prevent abnormal scar formation which can be aesthetically distressing to many patients [21]. It is also important to recognize that the force used to suture a knot cannot be too low or too high. Rodrigues et al study showed that small intestines started to damage at $1.6 \mathrm{~N}$ and rupture at $2.1 \mathrm{~N}$, whereas large intestines start to damage at $2.2 \mathrm{~N}$ and rupture at $3.0 \mathrm{~N}$ [22]. Similar for skin suturing, we are of the opinion that a suture tied using large forces would be painful, cause tissue damage, tissue scarring and even result in subsequent infection [23]. Knowing the optimum force can guide a clinician how much force should be exerted when tying a knot at any time of the day.

There are limitations to our study. Firstly, we have found that $3 \pm 0.5 \mathrm{~N}$ is the optimum range of tying force that should be used to tie a knot, but this force can only apply to a surgeon's knot with 3 throws tied with Prolene 4.0. Further studies must be done to find out the optimum force that is needed to tie a different material, knot technique and number of throws. Secondly, our study only applies to instrument tied knots such as Minimal Invasive Surgery. There are many knots in clinical practice that are hand tied. Thus, it still remained a challenge to determine how much force is used in a hand tied knot. Thirdly, although porcine skin is widely used in suturing studies, it is difficult to ensure that porcine skin can mimic human skin. For eg, the texture, thickness and tension might be different. Furthermore, skin at different locations have different tensions. Since different tissue types have their own individual range of acceptable forces before damage occurs [21], the force used to tie a knot might differ in skins at different sites with different characteristics. In this study, the first throw of the surgeon's knot was not measured.

The first throw had no taut when tied as it was to keep the suture in position. Regardless of the force used to tie the first throw, the suture would still be loose. Lastly, as this was an in vitro study, it only took into consideration the force required for knot slippage. The optimum force required to preserve other factors of skin healing such as vascularity was not considered.

\section{Conclusion}

we present a new experimental setup to test a knot configuration with different tying forces. Based on the static and cyclic testing, we found that $3 \pm 0.5 \mathrm{~N}$ is the optimum range of force needed to tie a surgeon's knot with 3 throws for maximal knot security using Prolene 4.0.

\section{Acknowledgements}

This study was supported by the Singapore Ministry of Health's National Medical Research Council under its Centre Grant (NMRC/ CG/M011/2017) and the Surgery Academic Clinical Program grant (Biomechanics Lab Programme). The authors would like to thank Mr Zeus Lim Yi Wei, BSc from Biomechanics Laboratory for his helps with manuscript preparation and submission.

\section{References}

1. Hanypsiak BT, Delong JM, Simmons L, Lowe W, Burkhart S, et al. (2014) Knot Strength Varies Widely Among Expert Arthroscopists. The American Journal of Sports Medicine 42(8): 1978-1984.

2. Livermore RW, Chong AC, Prohaska DJ, Cooke FW, Jones TL, et al. (2010) Knot security loop security and elongation of braided polyblend sutures used for arthroscopic knots. The American Journal of Orthopedics 39(12): 569-576.

3. Magilligan DJ, Deweese JA (1974) Knot security and synthetic suture materials. The American Journal of Surgery 127(3): 355-358.

4. Silver E, Wu R, Grady J, Song L (2016) Knot Security- How is it Affected by Suture Technique, Material, Size, and Number of Throws? Journal of Oral and Maxillofacial Surgery 74(7): 1304-1312.

5. Elkousy HA, Sekiya JK, Stabile KJ, Mcmahon PJ (2005) A biomechanical comparison of arthroscopic sliding and sliding-locking knots. Arthroscopy: The Journal of Arthroscopic \& Related Surgery 21(2): 204210 .

6. Muffly TM, Cook C, Distasio J, Bonham AJ, Blandon RE, et al. (2009) Suture End Length as a Function of Knot Integrity. Journal of Surgical Education 66(5): 276-280.

7. Gibbons CER, Thompson D, Sandow MJ (2008) Flexor Tenorrhaphy Tensile Strength: Reduction by Cyclic Loading. Hand 4(2): 113-138.

8. Ramirez OM, Tezel E, Ersoy B (2009) The Peruvian Fisherman's Knot. Annals of Plastic Surgery 62(2): 114-117.

9. Baums MH, Sachs C, Kostuj T, Schmidt-Horlohé K, Schultz W, et al. (2013) Mechanical testing of different knot types using high-performance suture material. Knee Surgery, Sports Traumatology, Arthroscopy 23(5): 1351-1358.

10. Lo IK, Ochoa E Jr, Burkhart SS (2010) A comparison of knot security and loop security in arthroscopic knots tied with newer high-strength suture materials. Arthroscopy 26(9 Suppl): S120-126.

11. Ilahi OA, Younas SA, Alexander J, Noble PC (2004) Cyclic testing of arthroscopic knot security. Arthroscopy 20(1): 62-68. 
12. Muffly TM, Espaillat-Rijo LM, Edwards AM, Horton A (2012) Operating Room Fatigue: Is Your Twentieth Surgical Knot as Strong as Your First? Journal of Surgical Education 69(2): 215-217.

13. Horeman T, Meijer E, Harlaar J, Lange J, van den Dobbelsteen J, et al. (2013) Force Sensing in Surgical Sutures. PLoS ONE 8(12): e84466.

14. Adeeb S, Hill S, Chapman C, Duke K, Beaupre L, et al. (2016) Biomechanical evaluation of the Nice knot. Int J Shoulder Surg International Journal of Shoulder Surgery 10(1): 15-20.

15. Lo IK, Burkhart SS, Chan K, Athanasiou K (2004) Arthroscopic knots: Determining the optimal balance of loop security and knot security. Arthroscopy: The Journal of Arthroscopic \& Related Surgery 20(5): 489502.

16. Taylor FW (1938) Surgical knots. Annals of Surgery 107(3): 458-468.

17. Neuhofer S, Wieser K, Lajtai G, Müller D, Gerber C, (2013) Surgical knot tightening: how much pull is necessary? Knee Surgery Sports Traumatology Arthroscopy 22(11): 2849-2855.

\section{ISSN: 2574-1241}

DOI: 10.26717/BJSTR.2019.17.002985

Wong Yoke Rung. Biomed J Sci \& Tech Res

(C) (P) This work is licensed under Creative

Submission Link: https://biomedres.us/submit-manuscript.php
18. Trimbos JB (1984) Security of various knots commonly used in surgical practice. Obstet Gynecol 64(2): 274-280.

19. Neuhofer S, Wieser K, Lajtai G, Müller D, Gerber C, (2013) Surgical knot tightening: how much pull is necessary? Knee Surgery, Sports Traumatology, Arthroscopy 22(11): 2849-2855.

20. Capek L, Jacquet E, Dzan L, Simunek A (2011) The analysis of forces needed for the suturing of elliptical skin wounds. Medical \& Biological Engineering \& Computing 50(2): 193-198.

21. Bayat A (2003) Skin scarring. BMJ 326(7380): 88-92.

22. Rodrigues SP, Horeman T, Dankelman J, Dobbelsteen JJVD, Jansen F-W, et al. (2011) Suturing intraabdominal organs: when do we cause tissue damage? Surgical Endoscopy 26(4): 1005-1009.

23. Rosenberg IL, Brennan TG, Giles GR (1975) How tight should tension sutures be tied? A controlled clinical trial. British Journal of Surgery Br J Surg 62(12): 950-951.

$\begin{array}{ll}\text { BIOMEDICAL } & \text { Assets of Publishing with us } \\ \text { RESEARCHES } & \text { - Global archiving of articles } \\ \text { ISSN: } 2574-1241 & \text { - Immediate, unrestricted online access } \\ \end{array}$

